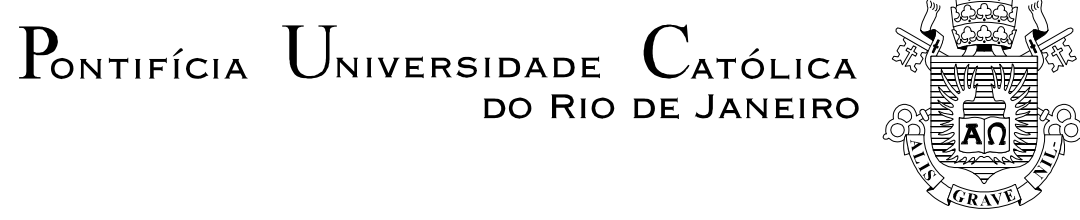

Leni Joaquim de Matos

Influência da Vegetação na Dispersão dos Sinais Rádio-Móveis

Tese de Doutorado

Tese apresentada ao Programa de Pós-Graduação em Engenharia Elétrica do Departamento de Engenharia Elétrica como parte dos requisitos parciais para obtenção do título de Doutor em Engenharia Elétrica.

Orientador: Prof. Gláucio Lima Siqueira

Rio de Janeiro Setembro de 2005 


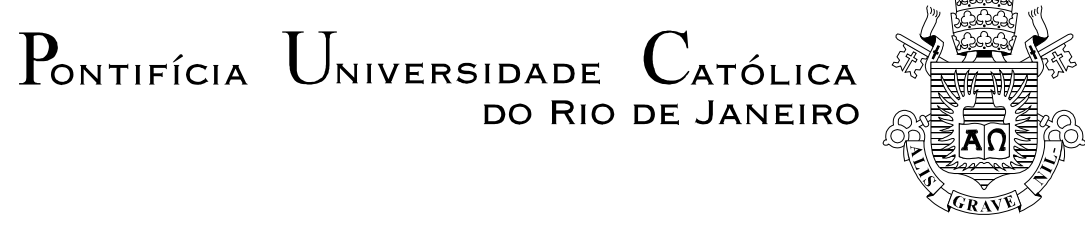

Leni Joaquim de Matos

\title{
Influência da Vegetação na Dispersão dos Sinais Rádio-Móveis
}

Tese apresentada como requisito parcial para obtenção do grau de Doutor pelo Programa de Pós-Graduação em Engenharia Elétrica do Departamento de Engenharia Elétrica do Centro Técnico Científico da PUC-Rio. Aprovada pela Comissão Examinadora abaixo assinada.

\author{
Dr. Gláucio Lima Siqueira \\ Orientador \\ Centro de Estudos em Telecomunicações - \\ PUC-Rio \\ Dr. Luiz Alencar Reis da Silva Mello \\ Centro de Estudos em Telecomunicações - PUC-Rio \\ Dr. Luiz Costa da Silva \\ Centro de Estudos em Telecomunicações - PUC-Rio \\ Dr. Julio César Rodrigues Dal Bello \\ UFF \\ Dr. Murilo Bresciani de Carvalho \\ UFF \\ Dr. Alexandre Santos de La Veja \\ UFF \\ Dr. Eduardo Javier Arancibia Vasquez \\ CLARO RJ/ES \\ Prof. José Eugenio Leal \\ Coordenador Setorial do Centro \\ Técnico Científico - PUC-Rio
}

Rio de Janeiro, 16 de setembro de 2005 
Todos os direitos reservados. É proibida a reprodução total ou parcial do trabalho sem autorização da universidade, da autora e do orientador.

\section{Leni Joaquim de Matos}

Graduou-se em Engenharia Elétrica com Habilitação em Eletrônica e Telecomunicações, na UERJ, em 1977. Obteve o título de Mestre em Ciências, no IME, em 1981. Lecionou em cursos de graduação de diversas universidades e em cursos de pós-graduação no IME e UnB. Desde 1985 é professora da UFF onde lecionou diversas disciplinas, foi coordenadora de curso de graduação, de extensão e vice-chefe de departamento. Atua como orientadora de projetos finais e de dissertações de mestrado, participa de bancas de graduação, de pós-graduação e de concursos para professores. Atualmente é Assessora de Ensino do Centro Tecnológico da UFF, leciona uma disciplina no curso de graduação e outra no de mestrado em Engenharia de Telecomunicações.

Ficha Catalográfica

Matos, Leni Joaquim de

Influência da vegetação na dispersão dos sinais rádiomóveis / Leni Joaquim de Matos ; orientador: Gláucio Lima Siqueira. - Rio de Janeiro : PUC-Rio, Departamento de Engenharia Elétrica, 2005.

215 f. ; $30 \mathrm{~cm}$

Tese (doutorado) - Pontifícia Universidade Católica do Rio de Janeiro, Departamento de Engenharia Elétrica .

Inclui bibliografia

1. Engenharia Elétrica - Teses. 2. Propagação em vegetação. 3. Sondagem em banda larga. 4. Parâmetros de dispersão. 5. Dispersão na vegetação. I. Siqueira, Gláucio Lima. II. Pontifícia Universidade Católica do Rio de Janeiro. Departamento de Engenharia Elétrica . III. Título. 


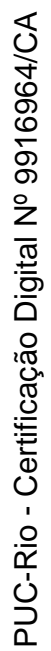

Ao meu esposo e filhos 


\section{Agradecimentos}

Ao professor orientador, Dr. Gláucio Lima Siqueira, pela grande cooperação no trabalho desenvolvido, amizade, estímulo e compreensão.

Ao Ex-Diretor e Professor do CETUC, PhD. Luiz Costa da Silva, pelo carinho com que me recebeu neste Centro e pela ajuda nos momentos em que necessitei.

Ao Dr. Júlio César Rodrigues Dal Bello, professor da UFF, pelo incentivo, apoio e cooperação.

Ao professor $\mathrm{MsC}$. Abelardo Podcameni pela ajuda nas dúvidas relacionadas à parte de componentes, equipamentos e medidas em RF.

Ao professor MsC. Marbey Mosso pela grande colaboração na confecção do oscilador de RF e pelas dúvidas por ele sanadas.

Ao Dr. Alexandre dos Santos de la Vega, professor da UFF, pela grande cooperação na parte de eletrônica, circuitos digitais e processamento de sinais.

Ao Dr. Murilo Bresciani de Carvalho, professor da UFF, pela paciência, incentivo e dedicação na parte de eletrônica e circuitos digitais, tanto no projeto quanto nos testes em laboratório.

Ao Engenheiro Frederico Fernandes Neves, cuja participação no projeto da parte digital e na apuração dos testes foi primordial para a execução da sonda.

Aos senhores funcionários do CETUC, aqui representados por Rogério Pereira da Silva e Brás Simão, pela inestimável contribuição na execução do projeto.

À ANRITSU Eletrônica Ltda, sempre pronta a colaborar, pelo empréstimo do gerador de RF para a realização das medições em campo.

Aos amigos do CETUC Robson, Luis Henrique, Janaína, Maurício, Glaucinho, Sidney, Fabrício, João Felipe, Eduardo, Bruno Palhares e Dudu que muito colaboraram tanto nas dúvidas, na prática de laboratório, programação como nas campanhas de medidas.

À UFF, especialmente ao Departamento de Engenharia de Telecomunicações, que me licenciou para que fizesse o meu aperfeiçoamento, permitindo o uso de seus laboratórios.

À PUC/RJ pela bolsa de isenção proporcionada, sem a qual não poderia realizar este curso. 


\section{Resumo}

Matos, Leni Joaquim; Siqueira, Gláucio Lima (Orientador). Influência da vegetação na dispersão dos sinais rádio móveis . Rio de Janeiro, 2005. 215p. Tese de Doutorado - Departamento de Engenharia Elétrica, Pontifícia Universidade Católica do Rio de Janeiro.

A influência da vegetação na dispersão dos sinais rádio-móveis é caracterizada através dos parâmetros de dispersão no tempo como o retardo médio, o espalha-mento de retardo e a banda de coerência, e dos parâmetros de dispersão na freqüência como o Doppler médio, o espalhamento Doppler e o tempo de coerência. Através do desenvolvimento e implementação de uma técnica de sondagem em faixa larga apropriada, medições foram realizadas em dois ambientes, das quais os parâmetros desejados puderam ser extraídos, por processamento. De posse de tais parâmetros, os ambientes vegetados puderam ser caracterizados e analisados e, com isto, os projetos dos sistemas rádio-móveis em ambientes semelhantes podem ser otimizados, sendo alguns exemplos desta melhoria: taxas de transmissão de bits mais adequadas evitando a interferência intersimbólica, o super dimensiona-mento dos sistemas e o uso desnecessário de equalizadores; limites mínimos de separação estabelecidos para a diversidade em freqüência e em tempo e limiares de ruído convenientemente estabelecidos.

\section{Palavras-chave}

Propagação em vegetação; sondagem em banda larga; parâmetros de dispersão; dispersão na vegetação; STDCC - Sweep Time Delay Cross Correlation. 


\section{Abstract}

Matos, Leni Joaquim; Siqueira, Gláucio Lima (Advisor). Influence of vegetation on dispersion of mobile radio signals. Rio de Janeiro, 2005, 215p. Doctorate Thesis - Departamento de Engenharia Elétrica, Pontifícia Universidade Católica do Rio de Janeiro.

The influence of vegetation in mobile radio signals dispersion is characterized by the time dispersion parameters like mean delay, delay spread and coerence bandwidth, and the frequency dispersion parameters like mean Doppler shift, Doppler spread and coerence time. An appropriate wideband sounding technique was developed and implemented. Using this technique, two vegeted environments were sounded. The results of calculated parameters from measurements were used to analyse and characterize the vegeted environments. Hence, mobile radio systems on these type of environments can be designed and optimized. Some examples of this optimization are: improvement on throughput, reduction of intersimbolic interference, unnecessary use of channel impairments avoidance techniques like equalizers, establishment of minimum limits for time and frequency diversity and the choice of suitable noise thresholds.

\section{Keywords}

Propagation in vegeted areas; wideband sounding; dispersion parameters; dispersion in vegeted areas; STDCC - Sweep Time Delay Cross Correlation. 


\section{Sumário}

$\begin{array}{ll}\text { 1. Introdução } & 13\end{array}$

2. Caracterização e Parâmetros de Dispersão do Canal Rádio-móvel 20

2.1. Canais determinísticos 21

2.2. Canais aleatórios $\quad 24$

2.3. Canais reais 26

2.4. Parâmetros de dispersão 31

2.4.1. Retardo médio $\quad 32$

2.4.2. Espalhamento de retardo (delay spread) 32

2.4.3. Banda de coerência $\quad 33$

2.4.4. Deslocamento Doppler 34

2.4.5. Espalhamento Doppler $\quad 36$

2.4.6.Tempo de coerência 36

3. Sistema de Medição Desenvolvido para a Sondagem 38

3.1. Técnica de sondagem STDCC $\quad 39$

3.2. Sonda STDCC Desenvolvida $\quad 50$

3.2.1. Geração do Sinal de Teste e Operações Realizadas 50

3.2.2. Simulações Realizadas no Sinal de Teste Transmitido 56

3.2.3. Especificação dos Componentes do Sistema Transmissor $\quad 59$

3.2.4. Especificação dos Componentes do Sistema Receptor 64

3.3. Calibração dos Osciladores $\quad 70$

3.4. Testes Iniciais $\quad 71$

3.5. Especificação das Antenas

4. Aquisição e Processamento dos Dados $\quad 75$

4.1. Aquisição das Medidas

4.2. Processamento das Medidas $\quad 77$

4.2.1. Cálculo do Retardo Médio 78

4.2.2. Cálculo do Espalhamento de Retardo 78

4.2.3. Cálculo da Banda de Coerência 78

4.2.4. Cálculo do Deslocamento Doppler $\quad 79$

4.2.5. Cálculo do Espalhamento Doppler $\quad 82$

4.2.6. Cálculo do Tempo de Coerência

4.2.7. Programação desenvolvida $\quad 83$

4.3. Set-up de Medição

5. Ambientes de Medidas $\quad 90$

5.1 Escolha das Rotas 90

6. Obtenção e Análise de Resultados 97

6.1 Análise em Pequena Escala 99

6.1.1 Análise da Dispersão de Sinal no Tempo 103 
6.1.2 Análise da Dispersão de Sinal na Freqüência

6.2 Análise em Larga Escala

7. Conclusões

Referências Bibliográficas

APÊNDICE A: Gerador de RF Desenvolvido no CETUC

APÊNDICE B: Esquemáticos, Layouts e Disposição dos Componentes nas Placas Impressas

APÊNDICE C: EPLD e Sistema Empregado para a sua Gravação

APÊNDICE D: Programação MATLAB Empregada na Aquisição das Amostras 


\section{Lista de Figuras}

Figura 1 - Modelo físico do canal no domínio do tempo 22

Figura 2 - Modelo físico do canal no domínio da freqüência 22

Figura 3 - Diagrama esquemático das funções do sistema 23

Figura 4 - Relações entre as funções de correlação do canal 26

Figura 5 - Relações entre as funções de correlação dos canais WSSUS 29

Figura 6 - Diagrama em Blocos do Sistema para Determinação da Resposta do Canal ao Impulso $\quad 40$

Figura 7 - Diagrama simplificado da sonda STDCC 44

Figura 8 - Curvas Características Normalizadas do Amplificadorde Potência 53

Figura 9 - Diagrama em Blocos para Análise do Sinal Modulado 54

Figura 10 - Operações Realizadas no Sinal de Referência 56

Figura 11 - Densidade Espectral de Potência do Sinal à Saída do PA 58

Figura 12 - Diagrama em Blocos do Sistema Transmissor 60

Figura 13 - Diagrama em Blocos do Bloco Digital do Sistema Transmissor

Figura 14 - Sistema Transmissor Desenvolvido 64

Figura 15 - Diagrama em Blocos do Sistema Receptor 64

Figura 16 - Circuito Integrador Empregado no Receptor 66

Figura 17- Diagrama Esquemático do Mixer mais Integrador 67

$\begin{array}{ll}\text { Figura } 18 \text { - Sistema Receptor Desenvolvido } & 70\end{array}$

Figura 19 - Densidade Espectral de Potência do Sinal Medido à Saída do PA 72

Figura 20 - Densidade Espectral de Potência da PN pura, com 5 Amostras/bit $\quad 72$

Figura 21 - Sistema de Aquisição das Medidas 76

Figura 22 - Perfil de Doppler Relativo à Rota JB2 80

Figura 23 - Sistema de Medição Empregado nos Testes 88

Figura 24 - Vista do Ambiente da PUC-RJ, Fotografada do Transmissor (Rota PUC1)

Figura 25 - Vista Aérea do Jardim Botânico do Rio de Janeiro

Figura 26 - Rotas de Medição na PUC-RJ e Local do Transmissor 92

Figura 27 - Rotas de Medição no Jardim Botânico-RJ e Local do Transmissor

Figura 28 - Rota 1/ Jardim Botânico 93

Figura 29 - Rota 9/ Jardim Botânico 93

Figura 30- Rota 3/ Jardim Botânico 93

Figura 31 - Rota 4/ Jardim Botânico 93

Figura 32 - Rota 6/ Jardim Botânico 94

Figura 33 - Rota 8/ Jardim Botânico 94

Figura 34 - Rota 2/ Jardim Botânico $\quad 94$

Figura 35 - Rota 7/ Jardim Botânico 99

Figura 36 - Rota 5/ Jardim Botânico 95

Figura 37 - Rota 10/ Jardim Botânico 95

Figura 38 - Rota 1/ PUC-RJ 95

Figura 39 - Rota 2/ PUC-RJ 95

Figura 40 - Rota 3/ PUC-RJ 96 
Figura 41 - Rota 4/ PUC-RJ 96

Figura 42 - Rota 5/ PUC-RJ 96

Figura 43 - Rota 5 (Vista da Tx) 96

Figura 44 - Características das Funções de Correlação do Canal WSSUS 98

Figura 45 - Perfis na rota JB1A $\quad 102$

Figura 46 - Perfil de Retardos da Rota JB3C 103

Figura 47 - Perfil de Retardos Reduzido da Rota JB3C 104

Figura 48 - Limiar de Fleury 117

Figura 49 - Variabilidade do Sinal Recebido nas Rotas 119

Figura 50 - Exemplo de um Perfil de Espalhamento Doppler da Rota JB2 121

Figura 51 - Perfil de Espalhamento Doppler da Rota JB7 122

Figura 52 - Perfil de Espalhamento Doppler da Rota JB5 123

Figura 53 - Perfil de Espalhamento Doppler da Rota PUC6 124

Figura 54 - Tempo de Coerência x Espalhamento Doppler para a Rota JB7A

Figura 55 - Tempo de Coerência x Espalhamento Doppler para a Rota PUC6

Figura 56 - Resposta Impulso: a) Rota PUC1 e b) Rota PUC6 131

Figura 57 - Resposta Impulso: a) Rota PUC1V e b) Rota PUC6V 132

Figura 58 - Perfis de Retardo ao Longo da Rota 133

Figura 59 - Perfis de retardo ao Longo da Rota JB1A 134

Apêndice A

Figura 1 - Diagrama em Blocos de um Circuito Oscilador 149

Figura 2 - Vista da Cavidade Ressonante 151

Figura 3 - Diagrama em Blocos do Gerador de RF 152

Figura 4 - Gerador de RF Desenvolvido no CETUC 153

\section{Apêndice B}

Figura 1 - Diagrama Esquemático do Bloco Digital do Sistema Transmissor 156

Figura 2 - Layout da Placa Impressa do Transmissor/Lado da Solda (L.S.) 157

Figura 3 - Layout da Placa Impressa do Transmissor/Lado dos Componentes 158

Figura 4 - Disposição dos Componentes na Placa Impressa do Transmissor 159

Figura 5 - Disposição dos Componentes na Placa Impressa do Receptor 160

Figura 6 - Layout do Circuito Mixer Mais Integrador 161

Figura 7 - Disposição dos Componentes na Placa Impressa do Mixer mais Integrador

Apêndice C

Figura 1 - Cabo de Conexão da Porta Paralela do PC à Placa de Teste 164

Figura 2 - Disposição Final dos Pinos de Entrada e Saída do EPLD 165 


\section{Lista de Tabelas}

Tabela 1 - Retardo e Banda de Coerência Relativos às Medidas na PUC/RJ

Tabela 2 - Retardo e Banda de Coerência Relativos às Medidas no Jardim Botânico/RJ

Tabela 3 - Rotas na Vegetação e Relação com os Retardos Eficazes

Tabela 4 - Doppler e Tempo de Coerência Relativos às Medidas na PUC/RJ

Tabela 5 - Doppler e Tempo de Coerência Relativos às Medidas no Jardim Botânico/RJ

Tabela 6 - Variação dos Parâmetros de Dispersão no Tempo, nos Grupos de Rotas

Tabela 7 - Variação dos Parâmetros de Dispersão na Freqüência, nos Grupos de Rotas 